\title{
An Investigation into the Impact of Social Networks on Entrepreneurial Opportunities
}

\author{
*Peyman Pournasr Khakbaz, Leyla Aghazadeh \\ Islamic Azad University, Science and Research Branch, Tehran, Iran \\ *p.pournasr@yahoo.com
}

\begin{abstract}
Social networks have various aspects affecting the identification of opportunities in some ways. The present paper aims at investigating the effects of social networks on entrepreneurial opportunities in the area of entrepreneurial businesses. The research method is descriptive-survey and practical. The statistical population is the social entrepreneurship managers. Data collection was conducted through scientist-made questionnaire with the reliability is best (0.92). Data analysis is conducted in two different levels of descriptive and deductive. In summation, social network have greatest impact on entrepreneurial opportunity via several ways that teaching and learning.
\end{abstract}

\section{Key words: Social networks, entrepreneurial opportunities, social entrepreneurship}

\section{Introduction}

Acquiring important information is a critical factor in the identification of opportunities. Some individuals have higher chance to find out opportunities as they have access to some information that others have not this chance. Interaction with other people is considered as an important way for acquiring information. People can benefit from social networks advantages in order to acquire information about entrepreneurial opportunities. The structure of the social network of an individual affects the quality and quantity as well as the speed of acquiring information. Thus, social networks can provide accessibility to the information accelerating the identification of opportunities. The relationships and ties between networks make it possible to people to have access to resources. Entrepreneurs need information, capital, skills and human resources in order to start their business activities. Although they have parts of these resources but this is the tie between resources, which completes their resources. The relations may include family relations, friends, acquaintances, old colleagues, customers and so on. Information itself is one of these resources. Social relations generally generate information channels reducing time and money to be spent for acquiring information. The social networks of entrepreneurs are among the ways helping people to acquire information about entrepreneurial opportunities.

The main hypothesis: social network affects opportunity identification

\section{Subsidiary hypotheses:}

- the power of network ties affects entrepreneurial alertness

- network activities affect entrepreneurial alertness

- the types of network ties affect entrepreneurial alertness

- entrepreneurial alertness affects opportunity identification

\section{Literature Review}

In Granovetter (1973) presented the theory of "weak and strong ties" and argued that new information is generally acquired through informal meetings (weak ties) instead of close friends (strong ties). He believes that the costs of retaining close ties restrict the number of strong ties while within social network one can have numerous weak ties. In addition, he argued that unfriendly relationships do not rely on a regular base, which results in higher information accessibility in weak ties compared with strong ties. His standpoint has been presented in entrepreneurship field with the title of "the power of weak ties". In contrast, Shockley et al (2002) argued that close interactions with other people are more valuable with respect to the quality of their information. He argued that network integrity leads to both on time data accessibility and accurate recovered data. Strong tied networks accelerate data flow between people. Sadler (2000) indicated that entrepreneurial networks are important for identifying opportunities. They founded their argument on Granovetter (1973) old paper with the title of "the power of weak ties" and declared that those entrepreneurs who benefit from widespread networks identify 
opportunities more compared with solo entrepreneurs. Roos and Roos (1997), Ardichvili (2000) and Kuratko et al (1993) indicated the influence of weak ties on the identification of opportunities. Singh believes that the size of network has positive and meaningful relation with opportunity identification. Ardichvili (2000) believes that entrepreneurial social network consists of weak ties and internal circles with which the entrepreneurs have long term and stable relations. These two factors provide entrepreneurs with the possibility of opportunity identification.

The structure of the social network of an individual affects the quality and quantity as well as the speed of acquiring information. Thus, social network can provide accessibility to the information accelerating the identification of opportunities (Barringer and Ireland, 2006). The first step of a business is the recognition of an opportunity (Cross et al., 2001). This step will be completed via conversation with family's members, friends and acquaintances (Gundry and Kichul, 2007). This type of relationships has been characterized as social network. Social network plays an important role in this step, as this is the social network that informs entrepreneurial opportunities. Social network provides financial, credit, control, resources, business and information supports. Entrepreneurial social network is considered as an "opportunity set" which provides entrepreneurs with insensible information as well as sensible resources. The identification of an opportunity or a set of opportunities will be more likely developed via social networks (Jack, 2010). Recognizing an opportunity is a result of an individual performance and his/her environments (Klyver et al., 2008). If entrepreneurs interact with their environment, this will enrich their ideas. In other words, personal characteristics as well as personal and social relationships play significant role in recognizing entrepreneurial opportunities (Leung et al., 2006). Levin and Cross (2004) suggests that the differences of individuals with respect to their social network affect their power of opportunity recognition. He has studied two aspects of the social network within which individuals are categorized: a) the differences of individuals in terms of the power of identifying opportunities with respect to the social network within which they have been categorized and b) the differences of individuals in terms of their potential interactions with the social network within which they have been categorized. He concluded that social network with plenty of weak ties cause the entrepreneurs to recognize entrepreneurial opportunities more. Ardichvili (2000) suggests that the identification, development and assessment of an opportunity will be initialized provided that the entrepreneurs have high levels of entrepreneurial alertness.

This alertness will be intensified when some parameters affect it simultaneously. In his view, these parameters include entrepreneurial alertness, primary knowledge and information, social network, personal characteristics and the type of the opportunity. Information plays significant role in the identification of opportunities by entrepreneurs. The entrepreneurs could empower himself / herself to acquire and interpret the information of special industries, available technologies and government policies via any possible way and use the obtained results for creating and developing his/her business. Making contact with other individuals is one of the potential sources in line with this object. Social network should be considered as a tie between individuals and organizations. The more these ties are the more entrepreneurial opportunities will be recognized. Bhagavatula and Elfring (2010) believe that information accessibility plays a significant role in identifying opportunities. In his view, individuals get opportunities through recognizing the value of the information they subjected to. Social network provide a substructure for entrepreneurs to acquire such information. The main object of this study is to define the impacts of social network on opportunity identification. In other words, we want to know which structures are created by social networks, which can help entrepreneurs to recognize opportunities. The history of social networks goes back to 1930 and organizational studies. The conceptual roots of this approach are hidden in three branches i.e.: sociology, anthropology and role theory (Ozgen and Baron, 2007). In recent years, the concentration of studies has significantly inclined towards networks and relationships between individuals, groups and organizations (Nicolaou and Shane, 2009).

\section{Methodology}

The present research is considered a practical research. The data is gathered through quantitative research method. In the quantitative stage, the survey method is used. The statistical population in the quantitative stage includes managers and employee of small and medium enterprise. The statistical sample was calculated and gathered according the sample volume estimation in unlimited population. A hundred and fifty individuals responded. Measurement error (E)in the formula, which shows the precision of the estimation, is $8 \%$ and certainty level $0.95 \%$. To maximize the sample volume, $\mathrm{p}$ and $\mathrm{q}$ values were assumed 0.5 . This way, the questionnaires were distributed among the respondents and 
finally 137 questionnaires were gathered (return rate, 91\%). The sampling method in the quantitative stage was random. Data was gathered with the help of interviews done with the managers and employees. Measurement scale in the questionnaire was the five-scale Lickert questionnaire ranging from "Completely disagree" to "Completely agree". In the qualitative stage, the research's repeatability or reliability increases by data and methods documentation while plan's implementation and by using qualitative standard methods. The system's validity is determined through service innovation experts counseling. In the quantitative stage of the study, in order to measure the measurement tool reliability, the Cronbach's alpha method was applied. The Cronbach's alpha value for questioner was 0.92 over allies. In addition, it should be mentioned that the questionnaire's validity was measured by experts during the interviews stage. Following gathering questionnaires and extracting data with respect to the questions, the data were entered into computer and we used data analysis method using LISREL software. For descriptive statistics, we used frequency distribution tables and curves. In order to assess the relations between the variables of the conceptual model of this study we used KMO.

\section{Results}

The investigation of the impacts of the following aspects of social networks on opportunity identification through entrepreneurial alertness:

- the power of network ties

- network activity level

- the types of network ties

As it is shown in the table, all the fit indices approve the pattern. Generally, if the GFI value is equal or higher than 0.98, it would be the sign of pattern is proper fit. On the other hand, RMSEA must be lesser than 0.05 and its confidence interval must not be very large, which in this pattern is about 0.035 . In addition, the values for NFI, CFI, and RFI, which are larger than 0.9 represent the patterns, section satisfactory level. The ratio of chi-squared to degree of freedom, as the most important index for pattern's fit determination, was less than 2 and equal to 1.57, which is in a suitable domain.

Table 1: Pattern has fit criteria

\begin{tabular}{lll}
\hline Criteria & Acceptable limit & The earned score \\
\hline Ratio of chi-squared to degree of freedom & Less than 2 & 1.8 \\
Root Mean Square Error of Approximation & Less than 0.05 & 0.035 \\
Goodness of Fit Index (GFI) & Larger than 0.98 & 0.99 \\
Comparative Fit Index (CFI) & Larger than 0.9 & 0.99 \\
Relative Fit Index (RFI) & Larger than 0.9 & 0.98 \\
\hline
\end{tabular}

After rationally proving the pattern has fit using the data, the significance of pattern's components and the relations between them was evaluated. All of these parameters indicate the simultaneous effectiveness degree of each observer and hidden parameter in the general pattern. Generally, the hidden parameters define $89 \%$ of the discovery opportunity dependant variable variance. That is, by using this pattern, $89 \%$ of the social network effective factors on discovery opportunity, which were in small and medium enterprise, were identified and $11 \%$ of the effective factors were not identified.

\section{Conclusion}

The results of this study indicate that the various aspects of social network including the strength of network ties, network activity and the types of network ties affect opportunity identification via their influence on entrepreneurial alertness. The results show that the strength of network ties has the maximum effect on entrepreneurial alertness, which is $43.8 \%$ while network activity has the minimum effect with $4.6 \%$. The results reveal that this is the strength of network ties, including weak and strong ties, which increases the alertness of the students of entrepreneurship faculty to entrepreneurial opportunities.

Suggestions: In the end, since the present research is considered one of the first studies conducted on the social network affect discovery opportunity, the suggestions below are given with the hope to develop and deepen this part of the knowledge, further suggestions for scholars:

- Doing exploration with the help of qualitative strategies of the research. 
- Conducting case studies about businesses created in the unique knowledge-based areas such as bio.

- Applying the research findings to independent businesses and developing a comparative chance.

Suggestions to policy-makers: In addition to theoretical suggestions mentioned above, some practical suggestions are given for nanotechnology managers and policy-makers:

- Improving these aspects and criteria in active entrepreneurs.

- Supporting discovery opportunity systems and attempting at implementing it to help entrepreneurs.

- Reducing the negative environments related to competencies and identifying the strengths of the competencies as well as presenting comprehensive plans to improve them in nanotech businesses.

\section{References}

Ardichvili, A. (2000). A theory of entrepreneurial opportunity identification and development. Journal of Business venturing, $18,105-123$.

Barringer, B. R. \& Ireland, R. D. (2006). Entrepreneurship: Successfully launching new Ventures. Pearson Prentice Hall.

Bhagavatula, S. \& Elfring, T. (2010). How social and human capital influence opportunity recognition and resource mobilization in India's handloom industry. Journal of Business Venturing, 25, 245-260.

Cross, R., Parker, A., Prusak, L. \& Borgatti, S. P. (2001). Knowing what we know: Supporting knowledge creation and sharing in social networks. Organizational Dynamics, 30(2), 100-120.

Granovetter, M. S. (1973). The Strength of Weak Ties. The American Journal of Sociology, 78(6), 13601380.

Gundry, L. K. \& Kichul, J. R. (2007). Entrepreneurship Strategy, Changing Patterns in New Venture Creation, Growth, and Reinvention. Sage Publications.

Jack, S. L. (2010). Approaches to studying networks: Implications and outcomes. Journal of Business Venturing, 25(1), 120-137.

Klyver, K., Hindle, K., \& Meyer, D. (2008). Influence of social network structure on entrepreneurship participation-a study of 20 national cultures. The International Entrepreneurship and Management Journal, 4(3), 331-347.

Kuratko, D., Hornsby, J., Naffziger, D. \& Montagno, R. (1993). Implementing entrepreneurial thinking in established organazation. Advanced mManagement Journal, 3, 28-34.

Leung, A., Zhang, J., Wong, P. K. \& Foo, M. D. (2006). The use of networks in human resource acquisition for entrepreneurial firms: Multiple fit considerations. Journal of Business Venturing, 21(5), 664686.

Levin, D. Z. \& Cross, R. (2004). The Strength of Weak Ties You Can Trust: The Mediating Role of Trust in Effective Knowledge Transfer. Management Science, 50(11), 1477-1490.

Nicolaou, N. \& Shane, S. (2009). Opportunity recognition and the tendency to be an entrepreneur: A bivariate genetics perspective. Organizational Behavior and Human Decision Processes, 110, 108117.

Ozgen, E. \& Baron, R. A. (2007). Social sources of information in opportunity recognition: Effects of mentors, industry networks, and professional forums. Journal of business venturing, 22(2), 174192.

Roos, G. \& Roos, J. (1997). Measuring your company's intellectual performance. Long Range Planning, $30(3), 413-426$.

Sadler, R. (2000). Corporate Entrepreneurship in the Public Sector: The Dance of the Chameleon. Australian Journal of Public Administration, 59(2), 25-43.

Shockley, G. E., Frank, P. M. \& Stough, R. R. (2002). Toward a Theory of Public Sector Entrepreneurship. NCIIA 7th Annual Meeting: BigIdeasin a Small World March 20-. Boston, Massachusett, 56. 